\title{
Application of the Vienna Classification for Crohn's disease to a single clinician database of 877 patients
}

\author{
Hugh James Freeman MD
}

\begin{abstract}
HJ Freeman. Application of the Vienna Classification for Crohn's disease to a single clinician database of 877 patients. Can J Gastroenterol 2001;15(2):89-93. An international working party at the World Congress of Gastroenterology held in Vienna, Austria from September 6 to 11, 1998 defined a classification for Crohn's disease based on patient age at diagnosis (eg, less than 40 years of age, 40 years of age or older), disease location (eg, terminal ileum, colon, ileocolon or upper gastrointestinal tract) and behaviour (eg, stricturing, penetrating). Disease location in the upper gastrointestinal tract was defined by disease being present proximal to the terminal ileum, regardless of terminal ileal or colon involvement. A 20-year, single clinician database of 877 patients from a university campus hospital was used, and comprised 492 women $(56.1 \%)$ and 385 men (43.9\%). Of these patients, $740(84.4 \%)$ were diagnosed before age 40 years and $137(15.6 \%)$ were diagnosed by 40 years of age or older. Disease was located in the terminal ileum alone in 222 patients $(25.3 \%)$, colon alone in 238 patients $(27.2 \%)$ and ileocolon in 304 patients (34.6\%). Another 113 patients (13.1\%) had disease in the upper gastrointestinal tract, usually with disease also in the terminal ileum (23 patients), colon (12 patients) or ileocolon (71 patients). Only seven of 877 patients had disease located in the upper gastrointestinal tract alone with no distal disease. Disease behaviour could be classified as nonstricturing and nonpenetrating in 256 patients (29.2\%), stricturing in 294 patients (33.6\%) and penetrating in 327 patients $(37.2 \%)$. Of the 877 patients with Crohn's disease, 837 were white, 38 were Asian and two were black. In this tertiary care setting of a single clinician practice in a Canadian teaching hospital at the University of British Columbia, Crohn's disease predominantly affects women, and young adults with a high rate of stricturing and penetrating complications.
\end{abstract}

Key Words: Behaviour; Crohn's disease; Disease location; Epidemiology; Vienna Classification

\section{Application de la classification de Vienne à une base de données de 877 patients atteints de la maladie de Crohn et suivis par un seul médecin}

RÉSUMÉ: Un groupe de travail international réuni lors du Congrès mon dial de gastro-entérologie tenu à Vienne en Autriche, du 6 au 11 septembre 1998, a établi une classification pour la maladie de Crohn selon l'âge du patient au moment du diagnostic (c.-à-d., moins de 40 ans ou 40 ou plus), la localisation de la maladie (c.-à-d. iléon terminal, côlon, iléo-côlon ou tractus digestif supérieur) et le type d'atteinte (p. ex. strictures, pénétration). La localisation de la maladie au niveau du tractus digestif supérieur a été définie par une maladie présente à proximité de l'iléon terminal, peu importe qu'il y ait ou non atteinte de l'iléon terminal ou du côlon. Une base de données échelonnées sur 20 ans, regroupant 877 patients d'un seul médecin attaché à un hôpital universitaire, a été utilisée et comprenait 492 femmes $(56,1 \%)$ et 385 hommes (43,9\%). Parmi ces patients, 740 (84,4 \%) ont reçu leur diagnostic avant l'âge de 40 ans et 137 (15,6 \%) ont reçu leur diagnostic à 40 ans ou plus. La maladie était localisée à l'iléon terminal seulement chez 222 patients (25,3\%), au côlon seulement chez 238 patients (27,2\%) et à l'iléo-côlon chez 304 patients (34,6 \%). Cent treize autres patients $(13,1 \%)$ présentaient une atteinte du tractus digestif supérieur habituellement, la maladie touchait également l'iléon terminal (23 patients), le côlon (12 patients) ou l'iléo-côlon (71 patients). Sept patients seulement sur 877 présentaient une maladie localisée uniquement au niveau du tractus digestif supérieur, sans maladie distale. Le type de maladie pouvait être classifié comme sans stricture ou sans pénétration chez 256 patients (29,2\%), avec stricture chez 294 patients (33,6\%) et avec pénétration chez 327 patients (37,2\%). Parmi les 877 patients atteints de la maladie de Crohn, 837 étaient de race blanche, 38 étaient de race asiatique et 2 étaient de race noire. Dans cet hôpital de soins tertiaires de l'University of British Columbia accueillant la pratique d'un seul gastro-entérologue, la maladie de Crohn affecte surtout les femmes et les jeunes adultes et on observe un taux élevé de strictures et de pénétrations sur le plan des complications.

Department of Medicine (Gastroenterology), University of British Columbia, Vancouver, British Columbia

Correspondence and reprints: Dr Hugh Freeman, Gastroenterology, ACU F-137, University of British Columbia Hospital, 2211 Wesbrook Mall,

Vancouver, British Columbia V6T 1W5. Telephone 604-822-7216, fax 604-822-7236

Received for publication February 1, 1999. Accepted April 23, 1999 
$\mathrm{I}^{\mathrm{n}}$ 1998, an international working party was organized for the World Congress of Gastroenterology, held in Vienna, Austria from September 6 to 11, 1998, to develop a consensus for data collection on patients with Crohn's disease (1). In part, this was due to inadequate tools for evaluation of Crohn's disease. Currently available instruments, such as the Crohn's Disease Activity Index and the Inflammatory Bowel Disease Questionnaire, were designed to permit evaluation of disease activity, from both physician and patient perspectives, for use in clinical trials of new and evolving therapies $(2,3)$. Significant shortcomings, however, have become evident. The Crohn's Disease Activity Index may not be entirely reliable because even experienced investigators exhibit considerable interobserver variation in scoring individual cases, if prospectively examined (4). A number of other indexes have been developed and reviewed (5), but their value for survey studies has not been demonstrated. In the Vienna Classification, the stated goals developed by the working group were to establish an international classification of patient subgroups based on objective biological variables to improve the homogeneity of study populations in clinical trials, and to establish a linkage of genetic or serological markers to specific phenotypes. Definitions in this classification were confined to age at diagnosis, location of disease and clinical behaviour of the disease. Additional areas for future data collection included sex, ethnicity, family history and extraintestinal features.

Although a number of studies have evaluated some aspects of the Canadian experience with Crohn's disease (6-13), no published data are available on the application of this classification to a clinical database from Canada. In the present article, the reports of 877 patients with Crohn's disease who were evaluated directly by a single clinician investigator with a specific focus on intestinal diseases were retrospectively reviewed. The results of this evaluation document the clinical experience of one gastroenterologist from a teaching hospital located on a university campus and reports of patients with Crohn's disease in metropolitan Vancouver, British Columbia that accumulated over a period of 20 years.

\section{PATIENTS AND METHODS}

Patients: A total of 877 patients with Crohn's disease were used for this evaluation. All patients were seen directly and investigated by the clinician, and a diagnosis of Crohn's disease was established based on clinical, radiological, endoscopic and histological criteria, as well as negative microbiological studies (14). In brief, diagnosis was usually based on the results of colonoscopic and/or histological studies showing a segmental or patchy inflammatory process within the colorectum, distal small intestine or both, often with histological features of a focal and/or granulomatous inflammatory process. In addition, endoscopic mucosal biopsy, or radiological evaluation of the upper gastrointestinal tract or both were usually done. When available, surgical materials were also reviewed. Patients with ulcerative colitis, ischemic colitis, 'indeterminate' colitis and microscopic forms of colitis, including collagenous colitis and lymphocytic colitis, were ex- cluded from the present analysis. A retrospective review of all patient records, including pathology reports and surgical materials, was completed by using the patient database that had been prospectively developed from Crohn's disease patients seen from 1979 to 1998 , inclusive. Virtually all patients (more than 99\%) in this evaluation were seen and evaluated at a teaching hospital during this 20-year period. A small number of patients were also evaluated (less than $1 \%$ ) at one of the other teaching hospital sites in Vancouver, British Columbia.

Definitions: The definitions used in the present evaluation related specifically to the age of the patient at the time of the diagnosis of Crohn's disease, location of Crohn's disease and the clinical behaviour of the disease. The following were defined by an international working party at the 1998 World Congress of Gastroenterology (1).

- A: The age when diagnosis of Crohn's disease was first definitively established by radiology, endoscopy, pathology or surgery.

- L: The location of involvement and the maximum extent of disease involvement at any time before the first resection. Minimum involvement for a location is defined as any aphthous lesion or ulceration. Mucosal erythema and edema are insufficient. For the following classifications, at least a small and large bowel examination are required:

- disease limited to the lower third of the small bowel with or without spillover into the cecum;

- any colonic location between the cecum and rectum with no small bowel or upper gastrointestinal involvement;

- disease of the terminal ileum and any location between the ascending colon and rectum; and

- any disease location proximal to the terminal ileum regardless of additional involvement of terminal ileum or colon.

- B: Behaviour for the following:

- inflammatory disease that never has been complicated at any time over the course of disease;

- stricturing disease defined as the occurrence of constant luminal narrowing demonstrated by radiological, endoscopic or surgical-pathological methods with prestenotic dilation or obstructive signs or symptoms without the presence of penetrating disease at any time over the course of the disease; and

- penetrating disease defined as the occurrence of intra-abdominal or perianal fistulas, inflammatory masses and/or abscesses at any time during the course of the disease. Perianal ulcers are also included, but postoperative intra-abdominal complications and perianal skintags are excluded. 


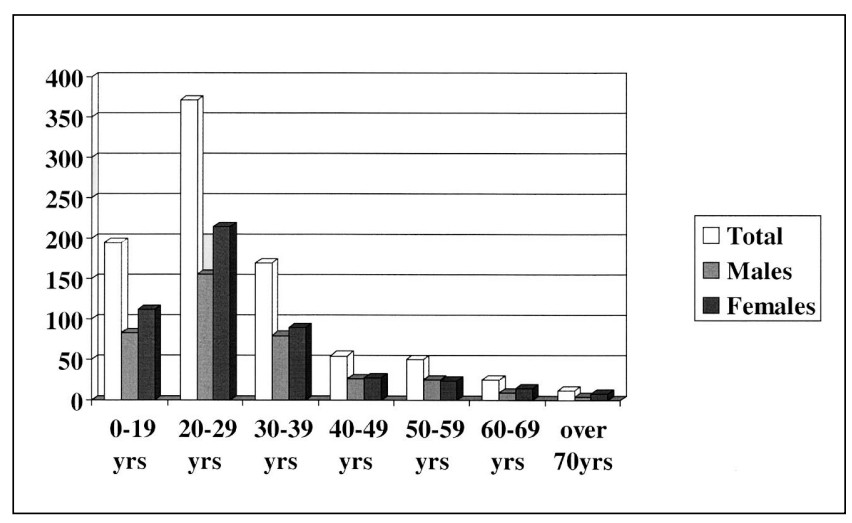

Figure 1) Age and sex distribution of 877 patients with Crohn's disease

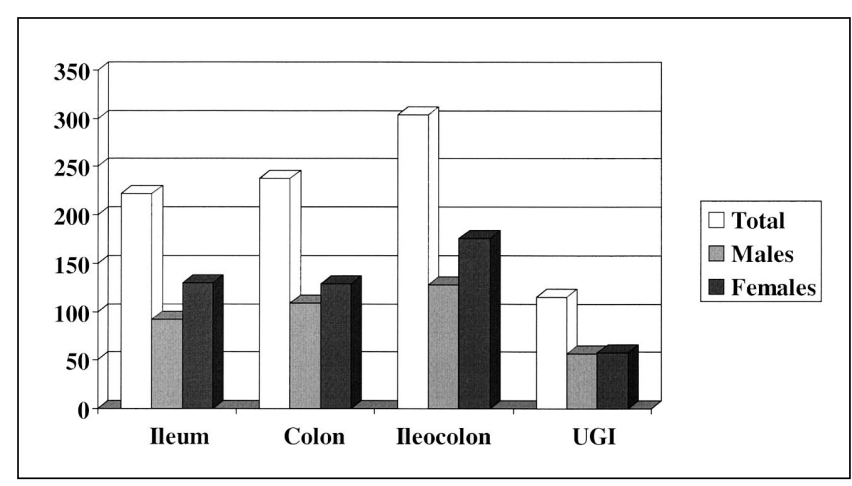

Figure 2) Distribution of disease location of 877 patients with Crohn's disease using the Vienna Classification. For this classification, disease detected in the upper gastrointestinal tract (UGI) predominates over disease detected at other sites

Vienna Classification used in the present study, disease detected in the upper gastrointestinal tract was considered to be the pre-eminent feature, even if disease was also present in the distal ileum or colon. While aphthoid or larger ulcerations were present in the upper gastrointestinal tract of 113 patients $(13.1 \%)$, only seven of the 877 patients (less than $1 \%)$ had disease localized in the upper gastrointestinal tract alone. There were 222 patients $(25.3 \%)$ who had disease in the terminal ileum alone, 238 patients $(27.2 \%)$ who had disease in the colon alone and 304 patients (34.6\%) who had disease in the ileum and colon. Of the 113 patients with disease in the upper gastrointestinal tract, including esophagus, stomach, duodenum and jejuno-ileum, 23 also had disease in the terminal ileum, 12 had disease in the colon and 71 had disease in the ileum and colon. Thus, if the predominance of upper gastrointestinal tract disease had not been considered in the Vienna Classification, there would be a total of 245 patients $(27.9 \%)$ with disease involvement in the terminal ileum without colonic involvement, 250 patients $(28.5 \%)$ with disease in the colon without ileal involvement and 375 patients $(42.8 \%)$ with disease in both the ileum and colon.

Figure 2 shows the distribution for sites of disease location in men and women based on the Vienna Classification. For both sexes, the majority of patients had ileocolonic involvement. Similar numbers of men and women had disease located in the ileum or colon alone, although there was a slight predominance in men for disease in the colon only compared with disease in the ileum only. Figure 3 shows the distribution for sites of disease location in men and women in the more traditional fashion by considering the ileum alone, colon alone and ileocolon. In Figure 3, only seven patients with upper gastrointestinal tract disease alone were represented. For both sexes, the majority of patients had ileocolonic involvement. Regardless of sex, men and women showed similar numbers of patients with disease located either in the ileum alone or in the colon alone, although there was a trend for the colon in men and ileum in women. Of the seven patients with upper gastrointestinal tract involvement alone, four were men and three were women. 


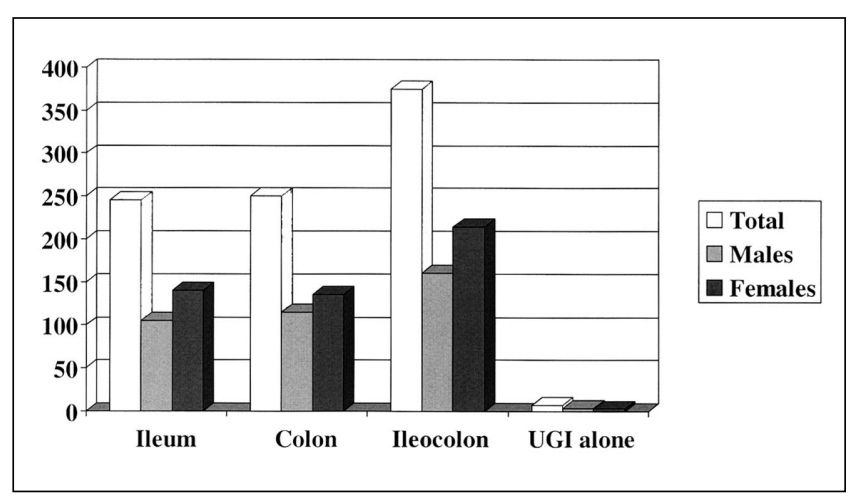

Figure 3) Disease location distribution of 877 patients with Crohn's disease using traditional classification based on primary sites of involvement, including ileum only, colon only and ileocolonic disease (and upper gastrointestinal [UGI] tract alone)

Clinical behaviour of disease: Although patients were often evaluated for the first time with features solely of penetrating disease (ie, presentation with ischiorectal abscess, free perforation, etc), concomitant strictures or stenoses were often present or frequently preceded the later development of an abscess or other penetrating complication of Crohn's disease. For the purposes of the Vienna Classification, however, detection of the features of penetrating or fistulizing disease is the predominant behaviour, regardless of the time that this may develop during the length of the follow-up period. In the 877 patients with Crohn's disease, disease behaviour could be classified for the course of the patient's disease as nonstricturing and nonpenetrating in 256 patients (29.2\%), stricturing in 294 patients $(33.6 \%)$ and penetrating in 327 patients (37.2\%).

Figure 4 schematically shows the distribution of Crohn's disease for all 877 patients and the findings in men and women for clinical behaviour based on the definition of the Vienna Classification: stricturing, penetrating, nonstricturing and nonpenetrating disease. Although penetrating complications occurred most often overall, the single most common clinical pattern observed in women was stricturing or stenosing disease.

Ethnicity: Of the 877 patients with Crohn's disease, 837 were white (95.4\%), 38 were of Asian descent (4.3\%) and two were black (less than $1 \%$ ).

\section{DISCUSSION}

In the present study, the demographics of patients with Crohn's disease from a single clinician investigative practice were explored. A total of 877 patients were evaluated during a 20-year period (from 1979 to 1998, inclusive) and, in this clinical tertiary care setting in a campus teaching hospital, the disorder was predominantly in women and initially diagnosed before age 40 years. During the course of clinical evaluation of the upper and lower gastrointestinal tracts, most patients were found to have a maximal extent of involvement in the distal ileum and colon. Finally, most patients with Crohn's disease investigated in this setting devel-

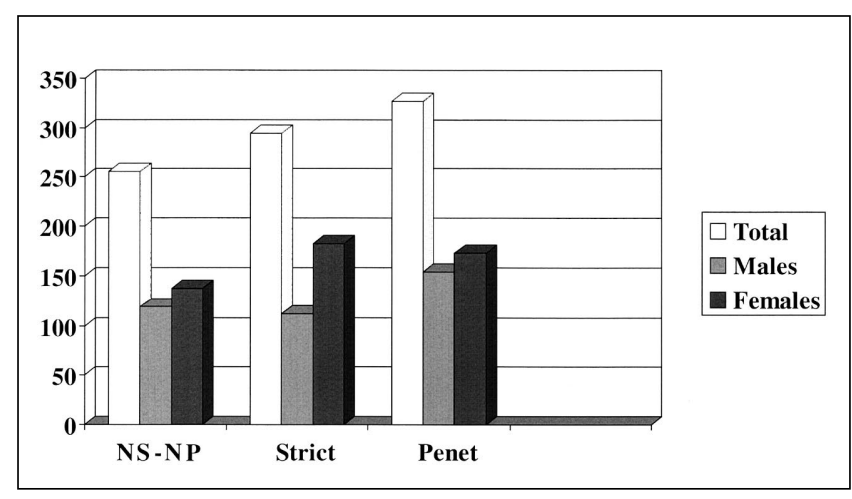

Figure 4) Disease behaviour in 877 patients with Crohn's disease. In the Vienna Classification, perforating complications during the course of clinical follow-up predominate over other forms of clinical 'behaviour' of the disease. NS Nonstricturing disease; NP Nonpenetrating disease; Strict Stricturing disease; Penet Penetrating disease

oped either stricturing or penetrating disease complications. These observations confirm and extend the findings reported in other epidemiological evaluations, including previously published Canadian studies from northern Alberta, southern Alberta and Ontario (6-9). In the report from northern Alberta (10), data were available from a total of 1716 patients with either Crohn's disease or ulcerative colitis who were admitted to one of five different teaching hospitals and evaluated by one of 10 separate clinical gastroenterologists in Edmonton, Alberta, before 1988. Data from these patients were retrospectively analyzed, largely for prevalence data for that geographical area. Chart records of patients with both Crohn's disease and ulcerative colitis were included, but no data were available for analysis of 703 additional patients with inflammatory bowel disease. The investigators estimated that about $48.5 \%$ of their patients had Crohn's disease, suggesting very similar numbers to the patients in the present report from a single practitioner, over a similar time frame of evaluation. In that study, as in the present report, the disease was predominantly in women, initially diagnosed before age 40 years and localized to the distal ileum and colon. Although the behaviour of Crohn's disease was not specifically evaluated in this northern Alberta study (at least as defined by the international working party for the 1998 Vienna Classification), the finding in the present report of $37.2 \%$ classified with penetrating disease is remarkably similar to the northern Alberta data (ie, about 45\% with penetrating complications, including abscess or fistula formation). Similarly, in smaller published studies $(11,12)$ from southern Alberta (ie, 509 patients with Crohn's disease) and southeastern Ontario (ie, 222 patients) from multiphysician groups, a predominance of women was noted. Moreover, in the Ontario study, a similar unimodal age distribution and primarily ileocolonic disease were seen. In conclusion, the demographic features of patients with Crohn's disease from Vancouver reported here were very similar to the observations in earlier Canadian studies, including a northern Alberta experience for patients residing mainly in Edmonton. 
A major objective of these earlier Canadian studies, however, was to define prevalence of disease, including Crohn's disease, in a particular geographical area. The data from the present report do not permit even an approximation of the prevalence of Crohn's disease in metropolitan Vancouver. A number of other issues, however, became evident as a result of using the Vienna Classification to evaluate the database. First, a relatively large number of patients were classified with upper gastrointestinal tract disease in the present report, in part, because virtually all patients had radiological and/or endoscopic and histological evaluation of the upper gastrointestinal tract and so the detection of disease, if present, would be expected to be high. Moreover, the classification schema, per se, preferentially selects patients for this disease location, even if more clinically significant disease is located elsewhere along the length of the small and large intestine. As a result, this modern survey classification may yield a substantially different distribution for disease location compared with earlier reports, such as the National Cooperative Crohn's Disease Study (15). In the present study, a more traditional distribution of disease was elicited if there was ileal disease alone, colonic disease alone or both ileal and colonic disease. Second, there have been concerns expressed for a schema that defines the clinical behaviour of this disease as penetrating or stricturing to reflect the presence of potentially serious perforating or obstructing compli-

\section{REFERENCES}

1. Gasche C, Scholmerich J, Brynskov J, et al. A simple classification of Crohn's disease: report of the working party for the World Congress of Gastroenterology, Vienna 1998. Inflamm Bowel Dis 2000;6:8-15.

2. Best WR, Becktel JM, Singleton JW, Kern F Jr. Development of a Crohn's disease activity index. Gastroenterology 1976;70:439-44.

3. Guyatt G, Mitchell A, Irvine EJ, et al. A new measure of health status for clinical trials in inflammatory bowel disease. Gastroenterology 1989;96:804-10.

4. Sandler RS, Jordan MD, Kupper LL. Development of a Crohn's index for survey research. J Clin Epidemiol 1988;41:451-8.

5. Yoshida EM. The Crohn's Disease Activity Index, its derivatives and the Inflammatory Bowel Disease Questionnaire: a review of instruments to assess Crohn's disease. Can J Gastroenterol 1999;13:65-73.

6. Gilbert JAL, Sartor VE. Regional enteritis. Disease patterns and medical management. Can Med Assoc J 1964;91:23-7.

7. Nootens J, Devroede G. Frequence de l'enterite regionale dans les cantons de l'Est. Union Med Can 1972;101:1138-40.

8. Grace M, Priest G. The epidemiology of inflammatory bowel disease. In: Thomson ABR, ed. Idiopathic Inflammatory Bowel Disease: cations of Crohn's disease, respectively, that, in some patients may occur independently. However, a strict classification of this type has not been universally accepted mainly because of the limited correlation between these definitions of clinical behaviour and the pathological changes reported in operative specimens. Finally, this classification's wide definition for penetrating disease to include all forms of perianal disease but excluding only perianal skin tags, and the pre-eminence for classification purposes of penetrating disease over stricturing disease may lead to an overrepresentation of penetrating disease compared with stricturing disease.

Using a recently developed classification for Crohn's disease devised at the 1998 World Congress of Gastroenterology, this single clinician experience from metropolitan Vancouver, British Columbia, confirms previously published Canadian experiences that Crohn's disease is a disorder that predominantly affects women and largely, although not exclusively, affects a youthful population with a very high frequency of significant penetrating (or perforating) and stricturing (or stenosing) complications. The use of this modern classification schema, recognizing its limitations, may readily permit the development of comparative databases for teaching centres and provincial registries for future studies including therapeutic trials with more homogeneous populations.

Crohn's Disease and Chronic Ulcerative Colitis. Ottawa: Canadian Public Health Association 1982;7:52-65.

9. Pinchbeck BR, Kirdeikis J, Thomson ABR. Epidemiology of ulcerative colitis and Crohn's disease. In: Freeman HJ, ed. Inflammatory Bowel Disease. Boca Raton: CRC Press, 1989;1:9-35.

10. Pinchbeck BR, Kirdeikis J, Thomson ABR. Inflammatory bowel disease in Northern Alberta. An epidemiologic study. J Clin Gastroenterol 1988;10:505-15.

11. Davis FG, Grace MG, Hershfield N. Inflammatory bowel disease incidence and prevalence in southern Alberta. Can J Gastroenterol 1990;4:187-92.

12. Depew WT, Medeiros J, Beck IT, Dacosta LR, Groll A. Clinical presentation and course of Crohn's disease in southeastern Ontario. Can J Gastroenterol 1988;2:107-16.

13. Riley R. Crohn's disease and ulcerative colitis: morbidity and mortality. Health Rep 1990;2:343-54.

14. Lennard-Jones JE. Classification of inflammatory bowel disease. Scand J Gastroenterol Suppl 1989;170:2-6.

15. Summers RW, Switz DM, Sessions JT, et al. National Cooperative Crohn's Disease Study: Results of Drug Treatment. Gastroenterology 1979;77:847-69. 


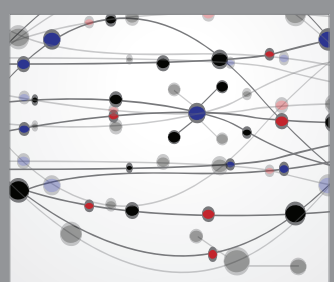

The Scientific World Journal
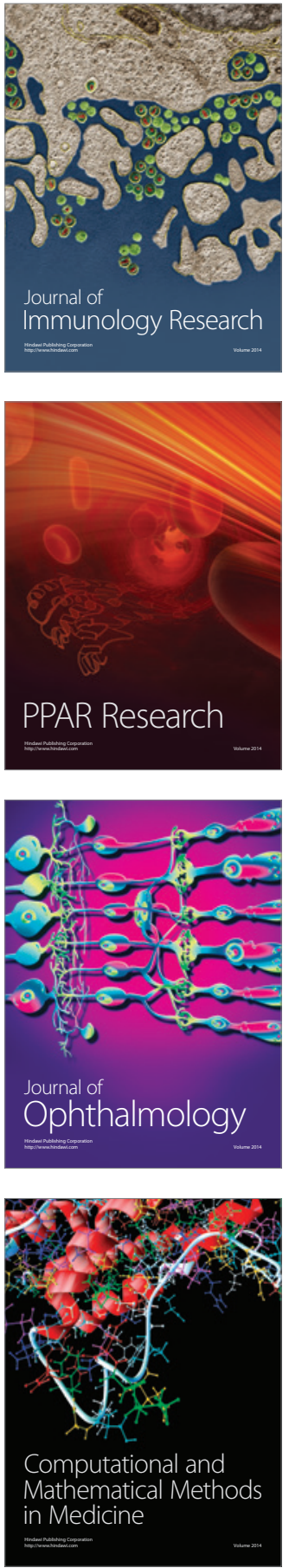

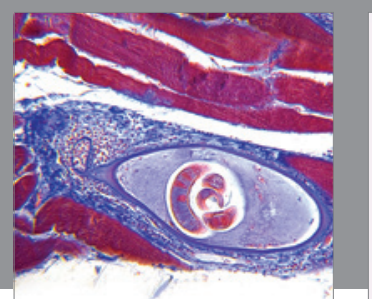

Gastroenterology Research and Practice

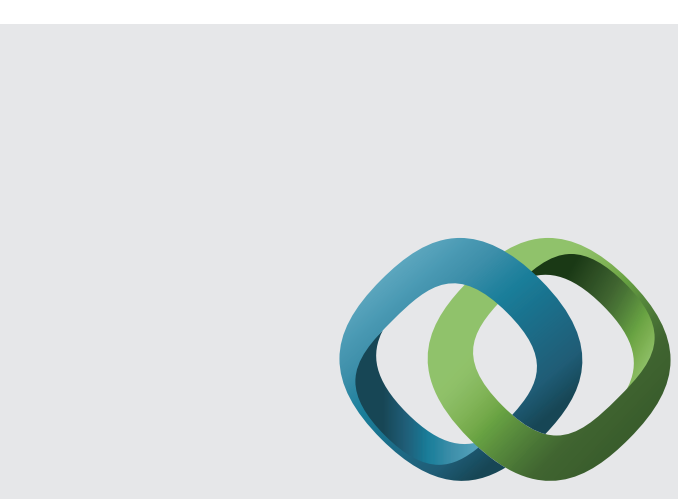

\section{Hindawi}

Submit your manuscripts at

http://www.hindawi.com
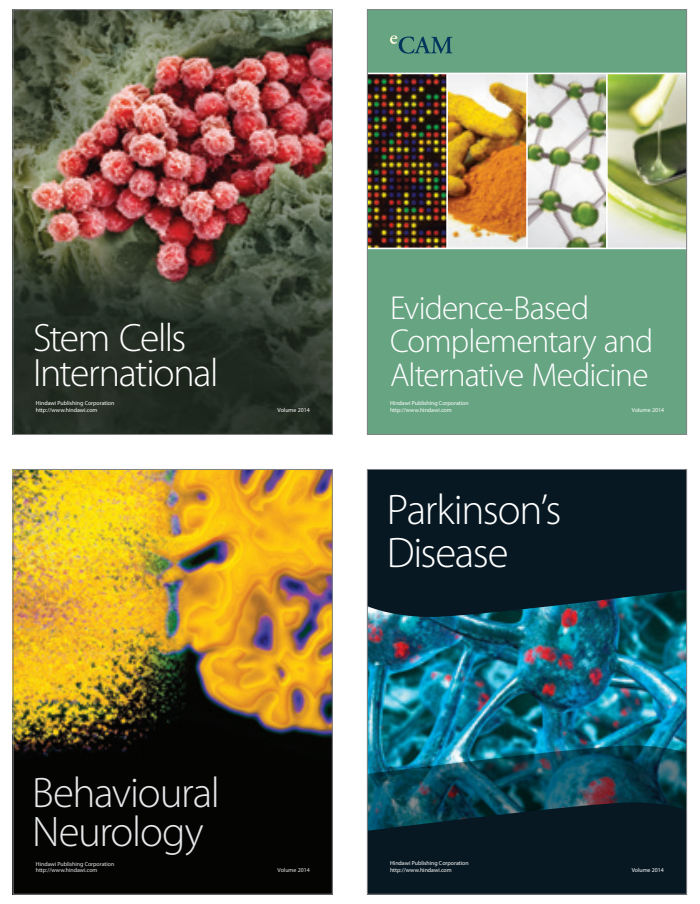
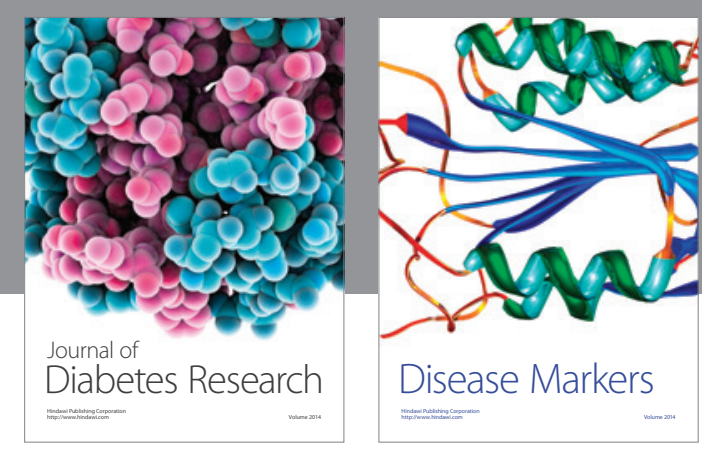

Disease Markers
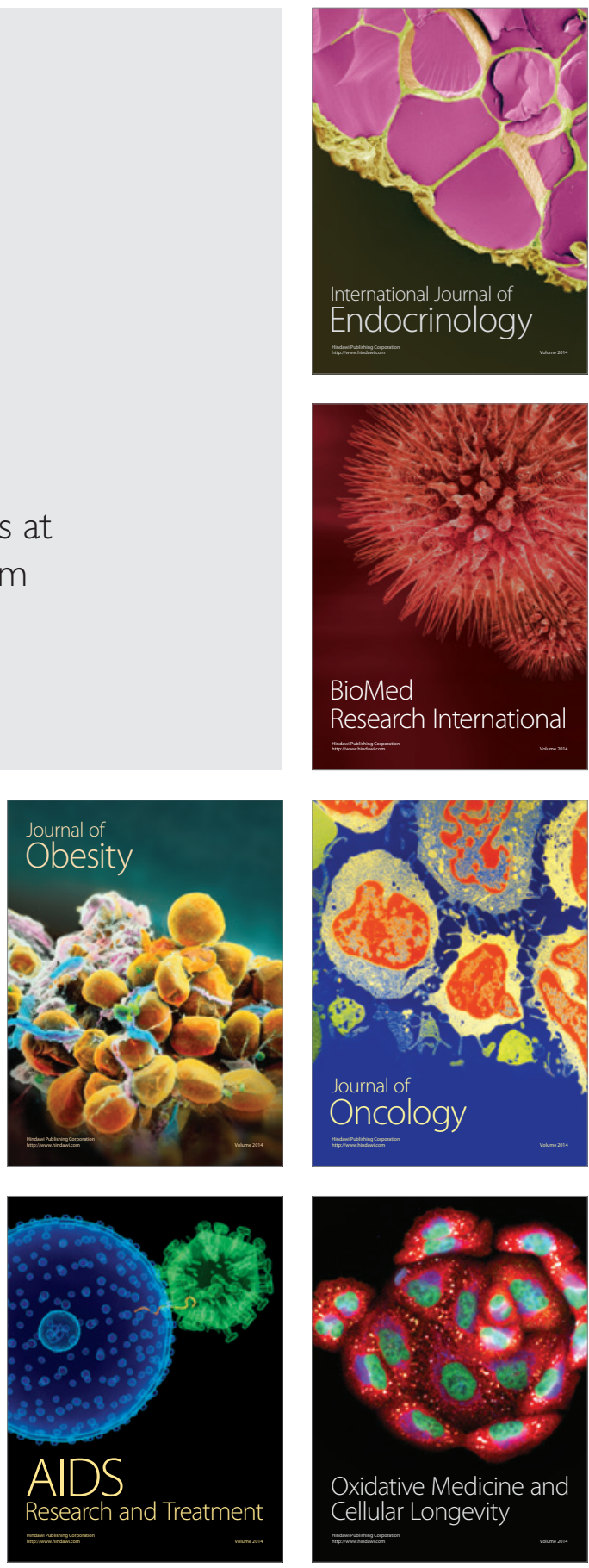